\title{
Reversible metamorphosis in coral planula larvae
}

\author{
Robert H. Richmond* \\ Smithsonian Tropical Research Institute, Apartado 2072, Balboa, Republic of Panama \\ and \\ Hawaii Institute of Marine Bíology, P.O. Box 1346, Kaneohe, Hawaii 96744, USA
}

\begin{abstract}
When planktonic planula larvae of the scleractinian coral Pocillopora damicornis settle, they secrete a calcareous exoskeleton for substrate attachment and metamorphose into a benthic polyp complete with mouth, tentacles, and mesenteries. If, however, these polyps are stressed within $3 \mathrm{~d}$ of settlement, they can retract all tissue from the skeleton and revert to a motile planktonic form resembling the initial larval stage. These 'secondary larvae' are capable of resettling and once again metamorphosing into a benthic polyp. Also, planulae may undergo a pelagic metamorphosis to a planktonic polyp with mouth and tentacles. This developmental plasticity permits an enhanced microhabitat selection ability, and has likely contributed to the broad dispersal of this pan-Pacific species.
\end{abstract}

\section{INTRODUCTION}

The scleractinian hermatypic coral Pocillopora damicornis is known to release numerous planula larvae monthly, throughout the year, on the reefs of Australia, Hawaii, and Micronesia (Marshall \& Stephenson 1933, Harrigan 1972, Stimson 1978, Richmond \& Jokiel 1984). The larvae are approximately $1 \mathrm{~mm}$ in diameter, contain zooxanthellae upon release from the parent colony (Vandermeulen 1974), and usually settle within $2 \mathrm{~d}$ of their release, although some individual larvae may remain planktonic (not necessarily competent) for periods exceeding 6 mo (Harrigan 1972, Connell 1973). P. damicornis planulae are energy rich, containing approximately $70 \%$ lipid by body weight, with a caloric content averaging around 7.5 calories per milligram ash free dry weight (Richmond 1982, 1983). The widespread distribution of this species throughout the Pacific Ocean, Indian Ocean, and Red Sea (Wells 1954, Veron \& Pichon 1976, Glynn 1977) may be a result of these high-energy values, which are likely to affect the length of planktonic life and the period during which larvae remain competent to settle.

This paper describes phenomena observed during competency experiments on Pocillopora damicornis planulae, which indicate a plasticity in metamorphosis not previously observed, nor thought possible based on

\footnotetext{
- Mailing address: Smithsonian Tropical Research Institute Apartado 2072, Balboa, Republic of Panama
}

developmental and energetic criteria. The results are discussed with respect to the dispersal potential of $P$. damicornis larvae, and the implications of the observed phenomena to the distribution of the species.

\section{MATERIALS AND METHODS}

Planulae used in this study were collected from adult colonies of Pocillopora damicornis from both Enewetak Atoll, Marshall Islands, and Kaneohe Bay, Oahu, Hawaii. Adult colonies were placed in 3 to 51 containers maintained at a seawater flow rate of 0.5 to $11 \mathrm{~min}^{-1}$, which overflowed into planulae collectors made from plastic beaker bases with walls constructed from $180 \mu \mathrm{m}$ plankton netting. Planulae released by the corals were removed from the collectors each morning, placed into glass specimen bowls, and counted. For additional details on techniques used for collecting both parent colonies and larvae, see Richmond \& Jokiel (1984).

In this experiment, approximately 100 larvae were placed in a $350 \mathrm{ml}$ glass specimen bowl containing $0.45 \mu \mathrm{m}$ millipore-filtered seawater. The bowl was preconditioned by a $2 \mathrm{~d}$ soak in seawater, and had a microbial film on its inner surface. Larvae were left undisturbed in the laboratory at $24^{\circ} \mathrm{C}$, and exposed to light levels of approximately 10 microEinsteins $\mathrm{m}^{-2} \mathrm{~s}^{-1}$ (standard 40 Watt fluorescent lights). The bowl water was stagnant, not aerated, and no nutritional material was added. 
Within $24 \mathrm{~h}$, most larvae had settled and formed a calcareous exoskeleton. At about $72 \mathrm{~h}$ following settlement, some larvae had retracted all tissue to the centers of their exoskeletons yet remained attached to the calyx, while others had completely separated from their exoskeletons. To determine if resettlement of completely separated individuals was possible, 10 of these were removed and transferred to another preconditioned bowl containing aerated, unfiltered seawater $\left(26^{\circ} \mathrm{C}\right)$ and exposed to natural sunlight filtered by fiberglass roofing panels to approximately $1800 \mathrm{mi}-$ croEinsteins $\mathrm{m}^{-2} \mathrm{~s}^{-1}$ (noon solar radiation level).

To determine whether individuals which had retracted to the centers of their deposited exoskeletons after $3 \mathrm{~d}$ in the laboratory, but had not completely separated from the skeleton, were capable of resettling their initial calices, these individuals were gently flushed with a change of seawater, then placed under the same 'natural' conditions of light and temperature as the 10 larvae which left their exoskeletons completely.

This experiment was performed at Enewetak in December, 1981, again in January, 1982, and for a third time at the Hawail Institute of Marine Biology in March, 1982, using Pocillopora damicornis planulae from the Kaneohe Bay reef flat.

At Enewetak, additional planulae were maintained in $500 \mathrm{ml}$ glass flasks containing millipore-filtered seawater, which were washed every 2 to $3 \mathrm{~d}$ using a non-toxic detergent (Joy) to prevent the formation of an organic film, in an attempt to keep the larvae from settling. These flasks were maintained at the ambient natural seawater temperatures and light conditions previously described.

\section{RESULTS}

All of the planulae in the first experiment performed at Enewetak settled within $12 \mathrm{~h}$ of their introduction into the specimen bowl. Within 24 h of their introduction into the bowl, all had deposited exoskeletons fused to the substratum. In the 2 subsequent trials, approximately $90 \%$ of the larvae settled and deposited an exoskeleton within the same time period. While maintained under the presumably suboptimal laboratory conditions, the following responses were observed.

Initially (ca. $36 \mathrm{~h}$ after introduction of larvae into the specimen bowl) tissue began to recede from the margins of the exoskeleton, exposing the underlying calcareous matrix. Within $3 \mathrm{~d}$ of initial settlement, the tentacles were resorbed and all tissue was retracted to the center of the calyx, forming a sphere (Fig. 1). By the end of the fourth day, approximately $80 \%$ of these ciliated spheres became completely dissociated from

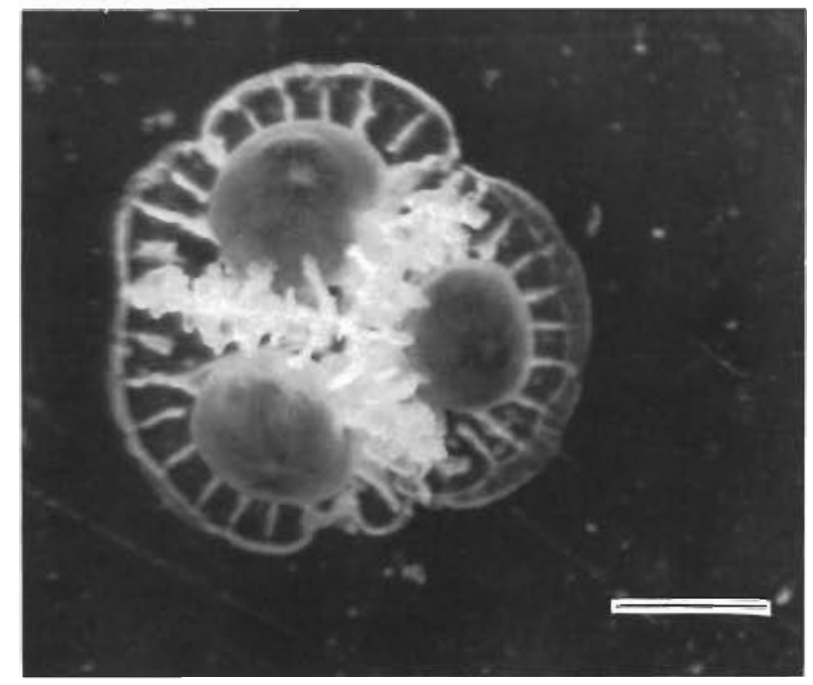

Fig. 1. Larvae retracted to the centers of their calices; scale: $1 \mathrm{~mm}$

their skeletons and began swimming freely or crawling along the substratum. Microscopic examination of vacated exoskeletons indicated no tissue remained on them (Fig. 2).

For the 3 trials of resettlement of completely separated 'secondary larvae' transferred to preconditioned vessels in flowing unfiltered seawater and natural sunlight, $3 / 10,1 / 10$, and $3 / 10$ individuals were observed to have secreted a new exoskeleton fused to the substratum, and once again metamorphosed into the polyp form. These numbers reflect only individuals which had re-metamorphosed within $48 \mathrm{~h}$ of introduction into the improved conditions.

Several of the secondary larvae in each of these trials continued to swim freely while extruding mesenterial filaments. When a homogenate of ground brine shrimp was placed near these individuals, ciliary currents were set up, pulling the homogenate over the filaments, which appeared well developed and functional.

Individuals which had retracted to the center of their initial calices, but had not yet become completely detached, could be induced to resettle on the original calyx by changing the environmental conditions to those more suitable for growth and survival. This was achieved by transferring the experimental vessels to outside water tables, with running seawater and exposure to sunlight. In such cases, a secondary exoskeleton was deposited within and on top of the first (Fig. 3). This resettlement was observed in 3 to 7 individuals per trial.

Data from the three separate trials indicated that the reverse metamorphosis from a settled, metamorphosed polyp with a calcified exoskeleton, to a motile form resembling the initial planula larva, took place only from the single polyp stage. Recruits that reached a 

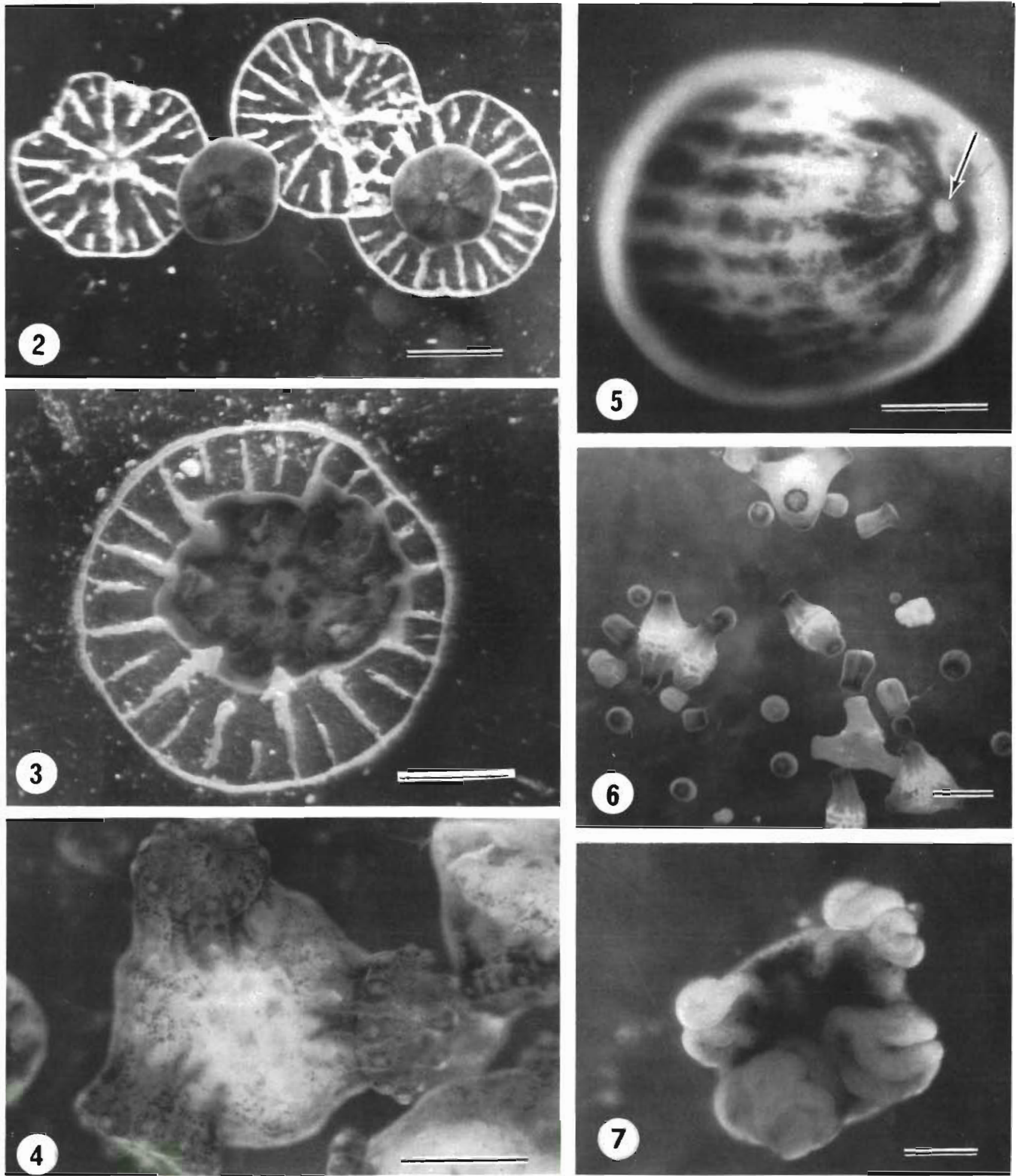

Fig. 2 to 7. Fig. 2: Larvae leaving their exoskeletons $3 \mathrm{~d}$ after initial settlement; scale: 1 mm. Fig. 3: Larva resettling and recalcifying within the original calyx when conditions improved prior to complete separation; scale: $0.5 \mathrm{~mm}$. Fig. $4:$ Calcified clusters of polyps, unattached to substrate and motile; scale: $1 \mathrm{~mm}$. Fig. 5: Planula exhibiting oral opening (arrow); scale: $0.3 \mathrm{~mm}$. Fig. 6: Partially metamorphosed larvae, some with tentacles and still planktonic; scale: 2 mm. Fig. 7 : Planula with extruded mesenterial filaments; scale: $0.5 \mathrm{~mm}$ 
multiple polyp stage ( 3 to 5 polyps, 6 to $8 \mathrm{~d}$ after settlement), were never observed to escape from the exoskeleton as a motile, viable 'larva'. When stressed for two weeks or longer, these colonies showed signs of tissue degradation, and subsequently died.

When the formation of an organic film was prevented by the frequent cleaning of the surfaces of the incubation vessel using a non-toxic detergent, some planulae were observed to settle against the aboral surfaces of other individuals. Clusters of 2 to 6 planulae fused while in the planktonic state, began the formation of the carbonate exoskeleton, and continued their metamorphosis into the polyp form (Fig. 4). Three to 5 such clusters commonly occurred per sample of 100 larvae. In this case, a negatively buoyant calcified colony formed, but remained unattached to the substratum. These calcified clusters are capable of locomotion along the substratum surface by means of cilia, and remained viable for periods exceeding 2 mo.

Planulae were also observed to undergo partial metamorphosis into a non-calcified 'planktonic polyp' form with mouth, tentacles and mesenterial filaments. Only solitary individuals were found to occur in this state (Fig. 5, $6 \&$ 7). Larval fusion and partial metamorphosis were observed at both Enewetak and Hawaii, with no apparent difference in rate of occurrence between the 2 sites.

\section{DISCUSSION}

The phenomenon described here as 'de-metamorphosis' from a settled, calcified and metamorphosed polyp and 'reversion to a larval form' is without precedent in the literature. In a recent review of settlement and metamorphosis of marine larvae, Chia (1980) stated, 'Settlement and metamorphosis usually occur in a relatively short period of time and neither is reversible'. The observations on Pocillopora damicornis larvae are a contradiction to previously defined notions of the unidirectionality of metamorphosis and the permanence of the sessile, benthic habit.

The observed reversion to a planktonic form in settled Pocillopora damicornis larvae is thus far a unique phenomenon not previously observed among marine benthic invertebrates, yet not totally without similarities to phenomena in related genera. De-differentiation of cells and tissue has been reported for species of Hydra and other cnidarians (Campbell 1974). Sammarco (1982) reported that in Seriatopora hystrix, a scleractinian coral in the same family as $P$. damicornis (Pocilloporidae), polyps may 'bail out' of their exoskeleton in adult colonies as a response to environmental stress, and subsequently resettle and recalcify, The secondary metamorphosis described here, however, is substantially different from polyp 'bail-out', as larvae are believed to be energetically constrained, requiring energy to undergo metamorphosis.

Planktonic larvae are considered to be limited in their ability to remain competent by their nutritional sources and energy reserves (Crisp 1974, Holland 1978). Pocillopora damicornis planulae, averaging 7.5 calories per milligram ash free dry weight and $70 \%$ lipid by body weight (Richmond 1982, 1983), clearly possess sufficient energy to undergo metamorphosis twice within a short time span. This may be further evidence in support of the value of symbiotic zooxanthellae to the larvae. Such larvae bridge the gap between planktotrophy and lecithotrophy (Thorson 1950, Scheltema 1971, Strathmann 1974), and thus may not suffer from the same constraints affecting other larval forms.

The observations on the ability of Pocillopora damicornis larvae to revert to a planktonic form by leaving an attached and secreted exoskeleton raise questions about the meaning of metamorphosis in these cnidarians. Complete metamorphosis in scleractinian planulae may be defined as consisting of 3 parts: (a) settlement and initial attachment to the substratum; (b) deposition of a calcareous exoskeleton fused to the substratum; (c) differentiation into a polyp form complete with a mouth, tentacles, mesenteries, and mesenterial filaments. Hence, the plasticity of development in $P$. damicornis larvae is further demonstrated by their ability for incomplete or partial metamorphosis.

A characteristic of Pocillopora damicornis planulae more adaptive for long-range dispersal is their ability to metamorphose into a free polyp form complete with mouth, tentacles, and mesenterial filaments, while remaining planktonic (Fig. 5, $6 \&$ 7). In this case, no skeletal material is secreted, and the larvae develop the ability to feed. It was previously believed that the larvae did not form an opening into the gastrovascular cavity, or tentacles, until after settlement and fusion to the substrate (Vandermuelen 1974). The abilities for partial metamorphosis as well as de-metamorphosis are consistent with the cnidarian level of development and in $P$. damicornis are clearly adaptations which increase the larva's dispersal potential.

My observations on Pocillopora damicornis planulae indicate that there may be a genetic component influencing the timing of settlement. An entire batch of planulae will settle immediately or within $24 \mathrm{~h}$ of release from the parent, while another group of larvae collected from a different head, but at the same time, and maintained under the same conditions, will exhibit prolonged planktonic existence. This temporal component is further reflected in the observations of 
larvae settling against one another in the water column when deprived of suitable substrata by preventing the formation of an organic film on experimental vessel surfaces (Fig. 4).

The ability of Pocillopora damicornis larvae to revert to the planktonic state after initial site selection and fusion to the substratum in an unsuitable environment, and subsequently resettle and recalcify, reflects utilizable energy reserves and results in enhanced microhabitat selection potential. The ability for partial metamorphosis into a 'planktonic polyp' capable of feeding, and, the possession of energy reserves and symbiotic zooxanthellae which translocate metabolites to the larvae (Richmond 1982), are all contributing factors in the successful widespread dispersion of this species throughout the Pacific Ocean.

Acknowledgements. Support for this work was provided by US Public Health Services Biomedical Research Support Grant 5507 RR07067-11 to the State University of New York at Stony Brook, and by the Lerner-Gray Fund, American Museum of Natural History. I thank Dr. P. Helfrich for the use of facilities at the Mid-Pacific Research Lab, and the Hawaii Institute of Marine Biology, and P. L. Jokiel, M. Hadfield, J. Levinton, P. M. J. Woodhead, D. Krupp, P. Sammarco, G. Hechtel and J. Graham for advice and comments. This is contribution no. 697 of the Hawail Institute of Marine Biology.

\section{LITERATURE CITED}

Campbell, R. D. (1974). Development. In: Muscatine, L. Lenhoff, H. M. (ed,) Coelenterate biology, reviews and new perspectives. Academic Press, New York, p. 179-210

Chia, F. (1980). Perspectives. Settlement and metamorphosis in marine invertebrate larvae. In: Chia, F., Rice, M. E. (ed.) Settlement and metamorphosis in marine invertebrate larvae. Elsevier North Holland Press, New York, p. 283-286

Connell, J. H. (1973). Population ecology of reef building corals. In: Jones, O, A., Endean, R. (ed.) Biology and geology of coral reefs II. Biology 1. Academic Press, New York, p. 205-246

Crisp, D. J. (1974). Energy relations of marine invertebrate larvae. Thallassia jugosl. 10 (1/2): 103-120
Glynn, P. W. (1977). Coral growth in upwelling and nonupwelling areas of the Pacific coast of Panama. J. mar Res. 35 (3): $567-585$

Harrigan, J. F. (1972). The planula larva of Pocillopora damicornis, lunar periodicity of swarming and substratum selection behavior. Ph. D. Dissertation, University of Hawaij

Holland, D. L. (1978). Lipid reserves and energy metabolism in the larvae of benthic marine invertebrates. In: Molins, D. C., Sargent, J. R. (ed.) Biochemical and biophysical perspectives in marine biology, 4. Academic Press, New York, p. 85-119

Marshall, S. M., Stephenson, T. A. (1933). The breeding of reef animals. Part I. The corals. Scient. Rep. Gt Barrier Reef Exped. Br. Mus. Nat. Hist. 3: 219-245

Richmond, R. H. (1982). Energetic considerations in the dispersal of Pocillopora damicornis planulae. In: Gomez, E. (ed.) Proc. 4th int. coral reef symp., Vol. 2. Manila, p. $153-156$

Richmond, R. H. (1983). Reproduction, larval physiology and dispersal potential of the coral Pocillopora damicornis. Ph. D. Dissertation, SUNY at Stony Brook

Richmond, R. H., Jokiel, P. L. (1984). Lunar periodicity in larva release in the reef coral Pocillopora damicornis at Enewetak and Hawaii. Bull. mar: Sci. 34 (2): 280-287

Sammarco, P. W. (1982). Polyp bail-out: an escape response to environmental stress and a new means of reproduction in corals. Mar. Ecol. Prog. Ser. 10 (1): 57-65

Scheltema, R. S. (1971). Larval dispersal as a means of genetic exchange between geographically separated populations of shallow-water benthic marine gastropods. Biol. Bull mar. biol. Lab., Woods Hole 140: 284-322

Stimson, J. S. (1978). Mode and timing of reproduction in some common hermatypic corals of Hawail and Enewetak. Mar. Biol. 27: 239-249

Strathmann, R. R. (1974). The spread of sibling larvae of sedentary marine invertebrates. Am. Nat. 108: 29-44

Thorson, G. (1950). Reproduction and larval ecology of marine invertebrates. Biol. Rev. 25: 1-45

Vandermuelen, J. H. (1974). Studies on reef corals. II. Fine structure of planktonic planula larva of Pocillopora damicornis, with emphasis on the aboral epidermis. Mar. Biol. 27: 239-249

Veron, J. E., Pichon, M. (1976). Scleractinia of Eastern Australia. Part 1. Monogr. Ser. Aust. Inst. Mar. Sci. 1: 1-86

Wells, J. W. (1954). Recent corals of the Marshall Islands. Prof Pap. U.S. geol. Sur. 260 (1): 385-486 